\title{
Cellular hamartoma resembling gastrointestinal stromal tumor: a solid tumor of the pancreas expressing c-kit (CD117)
}

\author{
Ursula Pauser ${ }^{1}$, Maria TS da Silva², Jörg Placke ${ }^{3}$, David S Klimstra ${ }^{4}$ \\ and Günter Klöppel ${ }^{1}$ \\ ${ }^{1}$ Department of Pathology, University of Kiel, Germany; ${ }^{2}$ Department of Pathology, University of Coimbra, \\ Portugal; ${ }^{3}$ Department of Pathology, Dinslaken, Germany and ${ }^{4}$ Department of Pathology, Memorial \\ Sloan-Kettering Cancer Center, New York, NY, USA
}

\begin{abstract}
Solid tumors of the pancreas are usually neoplastic. We report on two adult patients, each with a solid tumor of the pancreas that presented with an unusual histology and seemed to follow a benign course. The tumors, one located in the body and one in the tail, were well demarcated and composed of irregularly arranged but welldifferentiated acini and small intralobular and interlobular ducts embedded in predominantly hypocellular fibrotic tissue that contained fascicles of cytologically bland spindle cells. Islets were lacking, but immunohistochemical staining for chromogranin A and insulin revealed individual scattered insulin-producing cells distributed between acinar and ductal cells. The spindle cell component tissue showed coexpression of CD34, c-kit (CD117) and bcl-2. The follow-up (2 and 4 years) of the patients was uneventful. We propose to designate the tumors as 'cellular hamartoma resembling gastrointestinal stromal tumor.'
\end{abstract}

Modern Pathology (2005) 18, 1211-1216. doi:10.1038/modpathol.3800406; published online 1 April 2005

Keywords: pancreatic tumor; hamartoma; c-kit; CD34; bcl-2; differential diagnosis

Well-demarcated tumor-like lesions in the pancreas are uncommon. They have been described under the term pseudotumor ${ }^{1}$ or inflammatory pseudotumor. ${ }^{2}$ Recently, we described a tumorous lesion that we termed pancreatic solid and cystic hamartoma. ${ }^{3}$ Here we report on two further solid pancreatic tumors that have features in common with both hamartomas and gastrointestinal stromal tumors.

\section{Patients, materials and methods}

The cases were collected from the consultation files of the Department of Pathology of the University of Kiel, to which they had been submitted by the Department of Pathology in Dinslaken, Germany (case 1), and the Department of Pathology of the University of Coimbra, Portugal (case 2).

In the first case, a 51-year-old man without clinical symptoms had a routine check-up, during which a mass, $3 \mathrm{~cm}$ in diameter, was detected by ultrasonography in the tail of the pancreas next to

Correspondence: Dr U Pauser, MD, Department of Pathology, University of Kiel, Michaelisstr. 11, 24105 Kiel, Germany.

E-mail: upauser@path.uni-kiel.de

Received 3 December 2004; revised and accepted 24 January 2005; published online 1 April 2005 the splenic artery. This finding was confirmed by endosonography and CT. Laboratory tests were normal. As a result of the unclear nature of the tumor, abdominal surgery was performed with resection of the tumor.

In the second case, a 54-year-old woman with slight abdominal discomfort was examined by ultrasonography, which revealed a well-demarcated tumor, $2 \mathrm{~cm}$ in diameter, in the body of the pancreas. A left-sided pancreatic resection was performed to remove the tumor. Both patients had an uncomplicated postoperative course and so far (2 and 4 years, respectively) have relapse-free follow-up.

Representative $4 \mu \mathrm{m}$ sections of formalin-fixed, paraffin-embedded tissue from both specimens were stained with hematoxylin and eosin (H\&E) and periodic acid-Schiff. Immunohistochemical staining was performed using the standard avidinbiotin method against following antibodies: cytokeratin 8 (CAM 5.2, monoclonal, 1:10, Becton Dickinson Immunocytometry Systems, San Jose, CA, USA), insulin (monoclonal, 1:40, BioGenex, San Ramon, CA, USA), glucagon (polyclonal, 1:60, BioGenex), chromogranin A (monoclonal, 1:2, Linaris, Wertheim, Germany), somatostatin (polyclonal, 1:200, DakoCytomation, Glostrup, Denmark), pancreatic polypeptide (polyclonal, 1:5000, R.E. 
Chance, Indianapolis, IN, USA), trypsin (polyclonal, 1:1000; our laboratory), smooth muscle actin (1:20, DakoCytomation), CD34 (1:500, Immunotech, Marseille, France), bcl-2 (polyclonal, 1:25, DakoCytomation) and CD117 (polyclonal, 1:50, DakoCytomation). The proliferative activity was assessed by staining the tissue with the antibody Ki-S5 (equivalent to Ki-67 $7^{4}$.

\section{Results}

The pancreatic resection specimen of the first case contained a reddish-white well-demarcated nodule with a diameter of $3 \mathrm{~cm}$ and a homogeneous appearance on cut surface (Figure 1a). The resection specimen of the second case showed a similar tumor, except that it was smaller with a diameter of $2 \mathrm{~cm}$ (Figure 1b). The surrounding pancreatic tissue was regularly lobulated in both cases (Figure 2a) and showed no significant fibrosis.
Histologically, both tumors showed a disordered arrangement of pancreatic acini and intralobular and interlobular ducts lined by cuboidal and columnar epithelium. Islets were lacking. The well-differentiated acini and duct cells were embedded in a fibrous stroma showing areas with elongated spindle cells (Figure 2a,b) and, especially in case 2, paucicellular central sclerotic regions (Figure 2c). The acini stained positively for trypsin and the ductal cells for cytokeratin 8 (Figure 3). In addition, there were many scattered cells that were positive for chromogranin and insulin (Figure 4). Glucagon, somatostatin and pancreatic polypeptide cells were lacking. There was strong immunostaining for CD34 (Figure 5a) in the elongated spindle cells in the fibrous tissue of the lesion as well as in capillary vessel walls. c-kit expression (Figure 5b) was seen in the fibrotic stroma of the lesion, especially at the border with adjacent pancreatic tissue and in single exocrine cells in disorderly acini. Scattered c-kit positive mast cells were
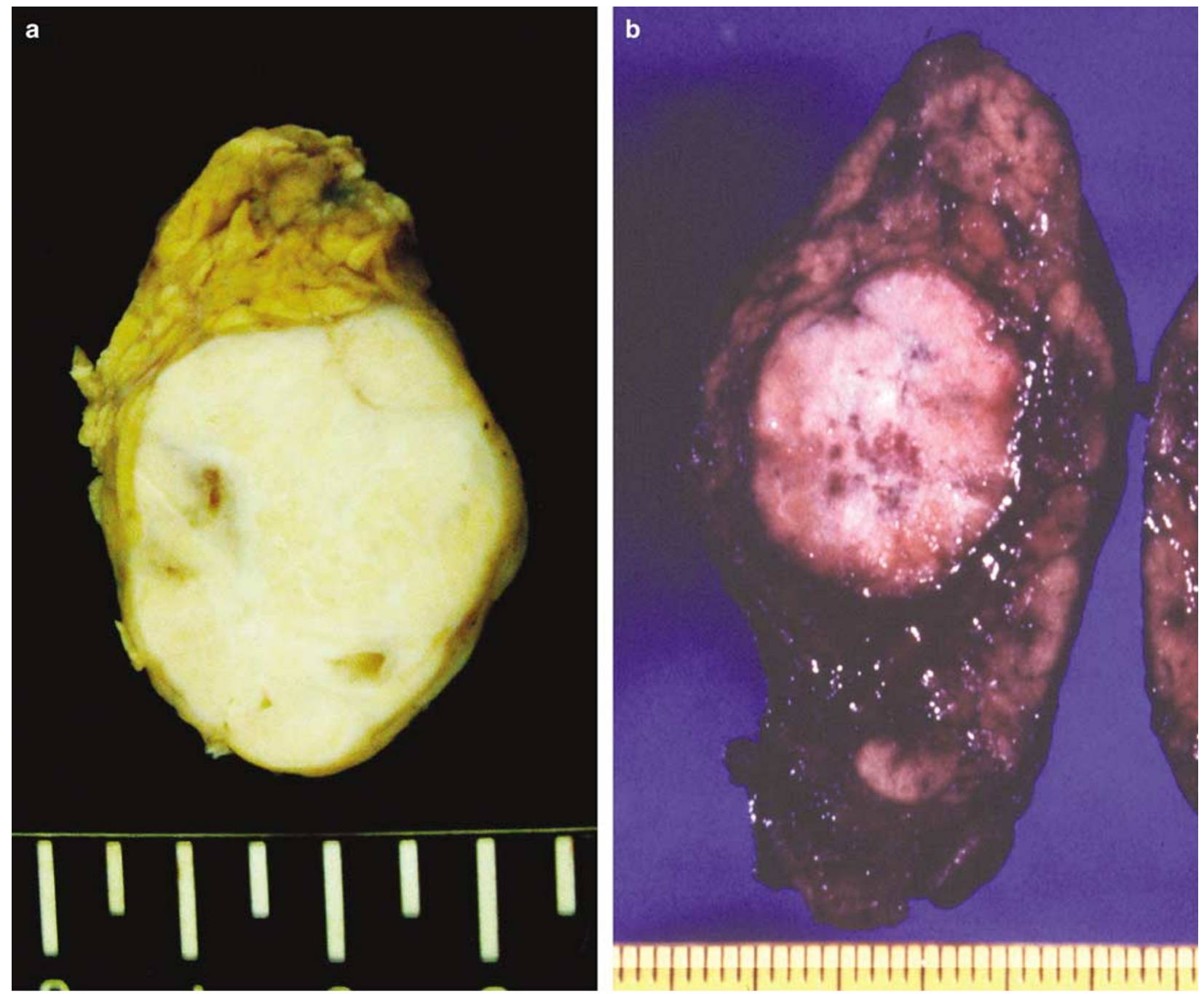

Figure 1 Macroscopic appearance of pancreatic resection specimens of case 1 (a) and case 2 (b) showing a well-demarcated homogeneous reddish-white tumor. 

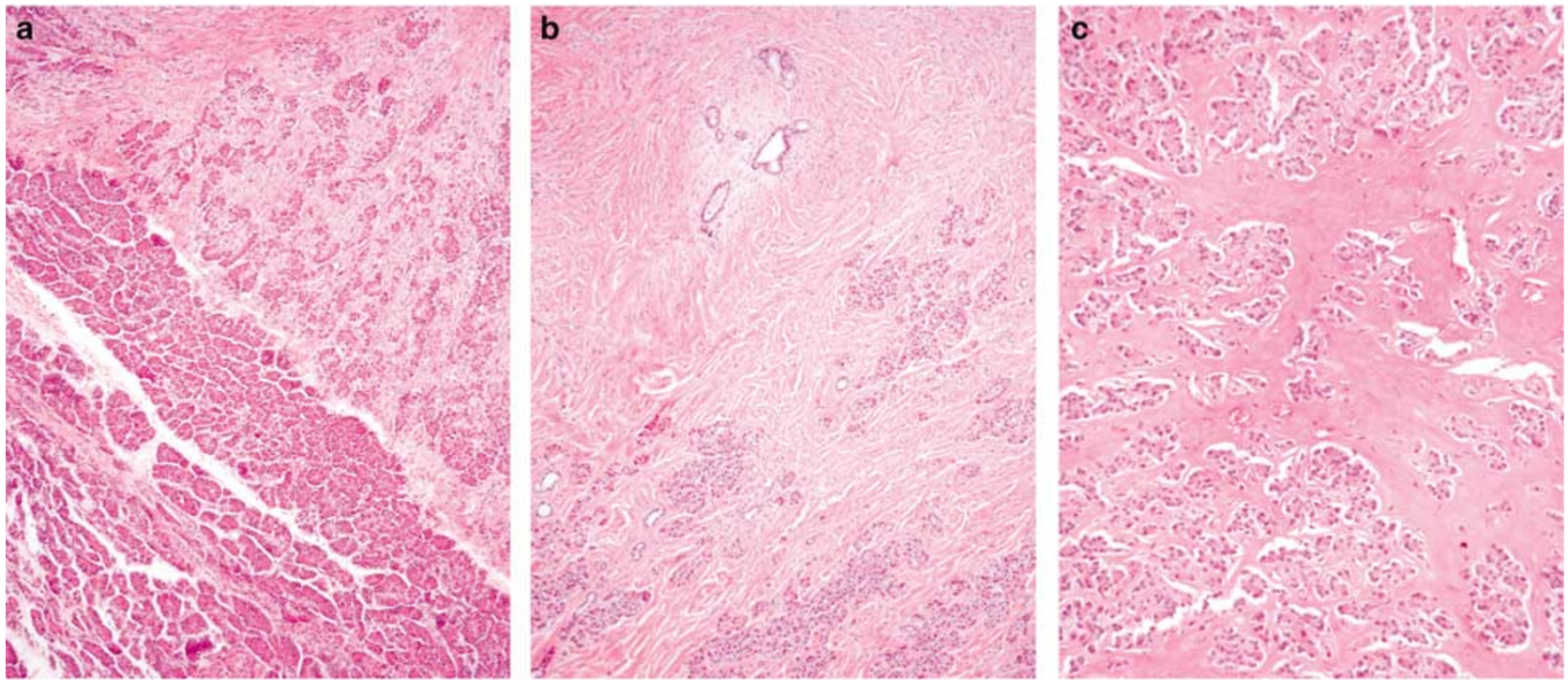

Figure 2 A circumscribed lesion is seen next to regularly lobulated pancreatic parenchyma (a). The lesion consists of well-differentiated acini and ducts embedded in fibrotic stroma (b) and focally paucicellular sclerotic stroma (c).

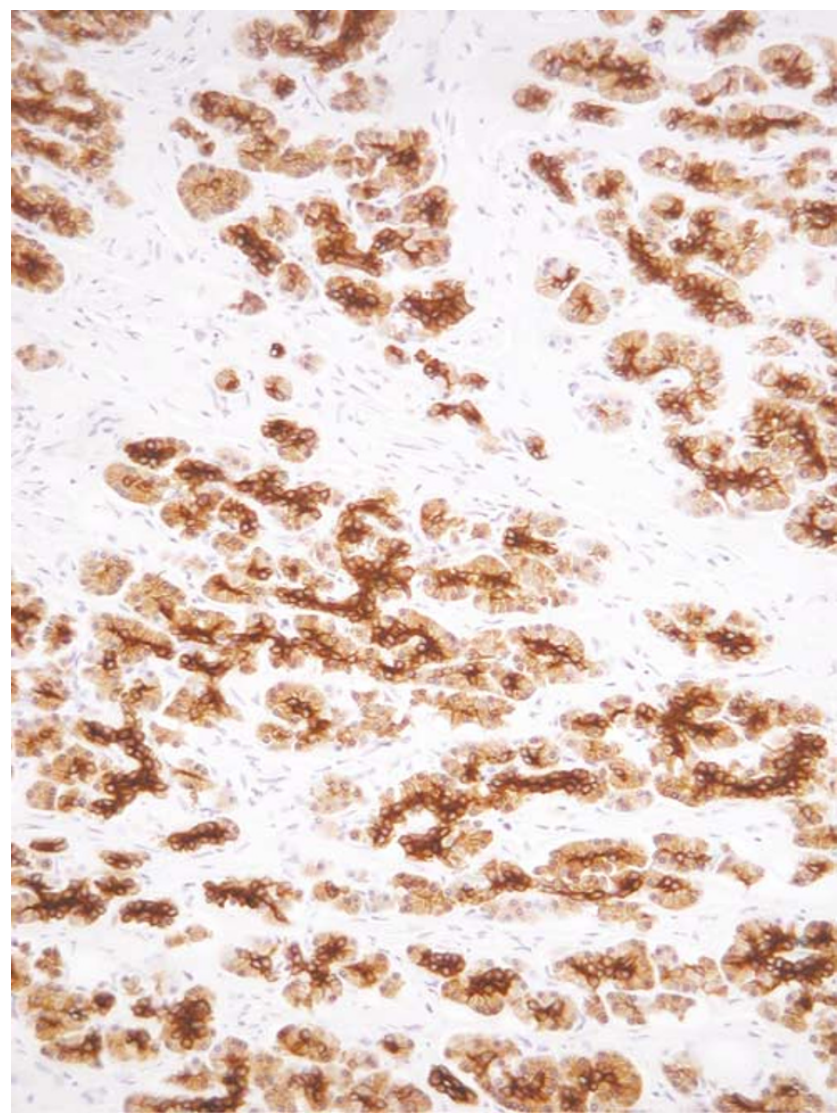

Figure 3 Strong cytokeratin 8 immunoreactivity accentuates the disorderly arrangement of acini.

detected in the adjacent pancreatic tissue. c-kit was coexpressed with bcl-2 in the fibrotic tissue in both cases. Smooth muscle actin was only expressed in

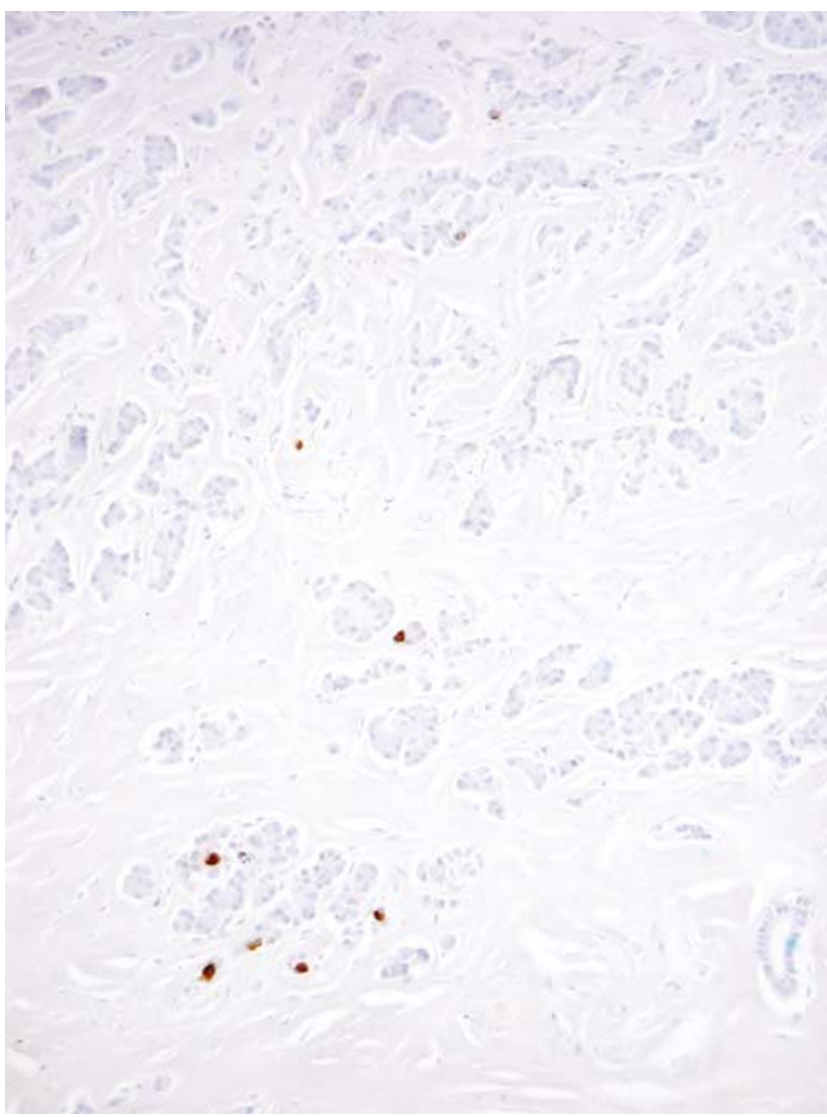

Figure 4 Single scattered endocrine cells throughout the exocrine tissue are immunostained by insulin. Islets are lacking.

the cells of vessel walls. Proliferating cells, identified by Ki-S5, though very rare, were found in the stroma of the tumors. 

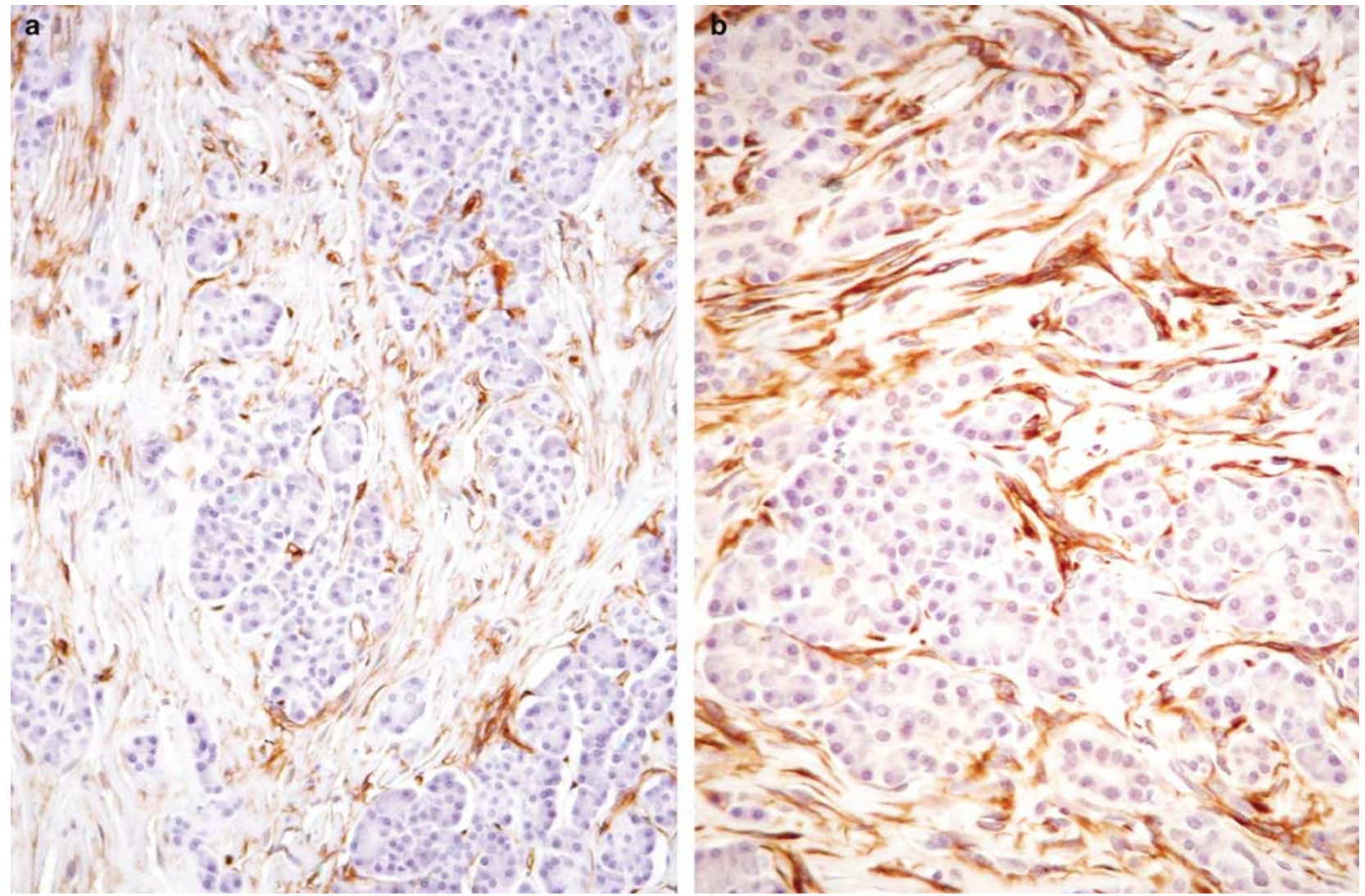

Figure 5 Strong CD34 (a) and CD117 (b) immunostaining is seen in elongated spindle cells in the fibrous tissue of the lesion.

\section{Discussion}

Solid tumors of the pancreas with a firm consistency usually turn out to be ductal adenocarcinomas. In rare cases such tumors are endocrine neoplasms with a prominent stromal component, mesenchymal neoplasms, such as leiomyosarcomas, malignant peripheral nerve sheath tumors, solitary fibrous tumors or inflammatory pseudotumors. The two solid tumors we observed do not fit into any of these categories, but show features reminiscent of hamartomas and gastrointestinal stromal tumors. Endocrine neoplasms, leiomyosarcomas, malignant peripheral nerve sheet tumors and solitary fibrous tumors were easily excluded, since neither the histological nor the immunohistological features of our tumors had anything in common with any of these neoplasms.

Recently, a number of inflammatory pseudotumors of the pancreas were described, ${ }^{2}$ which were composed of proliferating myofibroblasts and a lymphoplasmacytic infiltrate replacing endocrine and exocrine tissue. These tumors have been associated with autoimmune pancreatitis. ${ }^{5}$ Since the tumors that we observed did not show any inflammatory component, nor myofibroblasts, they certainly do not belong to the inflammatory pseudotumor family. Gallstones, alcohol or any other cofactors that may induce a tumor-like reaction can be excluded.

The main features of our tumors were a focally fibroblast-rich stroma and haphazardly distributed exocrine and endocrine tissue elements. An interesting finding was the coexpression of CD34, CD117 and bcl-2 in stromal cells. CD34, a myeloid stem cell marker, is known to be expressed by fibrocytes in neoplastic and inflammatory pancreatic lesions ${ }^{6}$ and seems to play an important role in maintaining stromal integrity and inhibition of tumor cell migration. ${ }^{7}$ It is also observed in solitary fibrous tumors, which may occur in the pancreas. ${ }^{8}$ Solitary fibrous tumors typically coexpress bcl-2 and CD34, ${ }^{9,10}$ but they are negative for CD117. ${ }^{11}$

CD117, a transmembrane tyrosine kinase receptor (KIT) of stem cell factor, is encoded by the protooncogene $c$-kit. The interaction between the kinase receptor and its ligand is essential for the development of melanocytes, erythrocytes, germ cells, mast cells and interstitial cells of Cajal. ${ }^{12-16}$ Gain-offunction mutations of the $c$-kit gene lead to stem cell factor-independent activation of intracytoplasmic signal transduction and finally tumor growth and differentiation. $c$-kit mutations have been found in mast cell tumors ${ }^{17}$ and gastrointestinal stromal tumors (GISTs), ${ }^{18}$ which are classified on the basis of 
their localization, growth pattern and CD117 immunoreactivity.

About two-thirds of GISTs coexpress CD34 $4^{19,20}$ and/or bcl-2..$^{9,10,21-23}$ Expression of c-kit, CD34 and bcl-2 in the stromal elements suggests a GIST, which may also occur outside the gut. The spectrum of pancreatic mesenchymal neoplasms was recently expanded by the description of an extragastrointestinal stromal tumor in the pancreas. ${ }^{24}$ The tumor consisted of spindle-shaped cells that were immunoreactive for vimentin, CD34 and c-kit. In contrast to our cases it lacked any pancreatic exocrine or endocrine component.

The focal overgrowth of mature normal tissue composed of exocrine and endocrine pancreatic cells in disorderly arrangement led us to the diagnosis of hamartoma. This term is defined as a benign tumor or tumor-like lesion composed of one or more tissues normal to the organ but abnormally mixed and overgrown. ${ }^{25}$ The mixture of mature cell types without atypical changes indicates that this may be a malformation rather than a neoplasm. The two tumors corresponded to the solid hamartoma in a premature infant described by Burt et $a l^{26}$ and were similar to one case reported by Anthony et al, ${ }^{1}$ except for the lack of islets. In 1977, Anthony et al reported three cases of pancreatic pseudotumor in adults. One of them, which consisted of lobulated connective tissue enclosing irregular, branching pancreatic ducts, acinar tissue and islet cells in a disorderly arrangement, without evidence of pancreatitis, fit the criteria of a hamartomatous lesion. The other two pseudotumors of the pancreas appear to have nothing in common with the lesions we observed. Burt et al described a lesion in a premature infant with refractory hypoglycemia and hypocalcemia whose entire pancreas consisted of noncystic ductal elements with a minority of wellorganized islets and acinar tissue, and called it fetal pancreatic solid hamartoma. The frequency of these lesions in infancy and childhood gives credence to the belief that they are developmental aberrations, meriting the designation hamartoma. In newborns, in addition to the well-formed islets situated in the central part of the lobules, numerous endocrine cell clusters and even single endocrine cells are scattered in the exocrine tissue.

In contrast to the recently described pancreatic solid and cystic hamartoma in adults, ${ }^{3}$ the two tumors in this study had a spindle cell stroma showing immunohistochemical coexpression of CD34, bcl-2 and c-kit, which is reminiscent of a gastrointestinal stromal tumor. In the differential diagnosis, a recurrent/metastatic GIST, which can also form a mass in the vicinity of the pancreas, was mentioned. However, there was no history of GIST in the two cases and in contrast to the reported stromal tumor of the pancreas, ${ }^{24}$ the disorderly endocrine and exocrine pancreatic tissue embedded in the stroma in our cases does not readily fit the diagnosis of GIST. The expression of c-kit is required for the diagnosis GIST, but c-kit expression is not specific to this tumor entity. Experimental studies $^{27}$ localized the c-kit protein to ducts of the fetal rat pancreas and to normal and hyperplastic ducts of the normal pancreas. ${ }^{28}$ Welsh et $a l^{29}$ postulated that tyrosine kinases may play a role in beta-cell replication, differentiation (neoformation) and survival, as ducts are thought to harbor beta-cell precursor cells. The CD34 and CD117-positive stroma cells in our two cases seem to be matrixproducing cells. The possibility that they are involved in the pathogenesis of the lesion is so far only speculation.

\section{References}

1 Anthony PP, Faber RG, Russell RC. Pseudotumours of the pancreas. BMJ 1977;1:814.

2 Palazzo JP, Chang CD. Inflammatory pseudotumour of the pancreas. Histopathology 1993;23:475-477.

3 Pauser U, Kosmahl M, Krušlin B, et al. Pancreatic solid and cystic hamartoma in adults: characterization of a new tumorous lesion. Am J Surg Pathol 2005, in press.

4 Kreipe H, Wacker HH, Heidebrecht HJ, et al. Determination of the growth fraction in non-Hodgkin's lymphomas by monoclonal antibody Ki-S5 directed against a formalin-resistant epitope of the Ki-67 antigen. Am J Pathol 1993;142:1689-1694.

5 Klöppel G, Lüttges J, Löhr M, et al. Autoimmune pancreatitis: pathological, clinical, and immunological features. Pancreas 2003;27:14-19.

6 Barth PJ, Ebrahimsade S, Hellinger A, et al. CD34+ fibrocytes in neoplastic and inflammatory pancreatic lesions. Virchows Arch 2002;440:128-133.

7 Bucala R, Spiegel LA, Chesney J, et al. Circulating fibrocytes define a new leukocyte subpopulation that mediates tissue repair. Mol Med 1994;1:71-81.

8 Lüttges J, Mentzel T, Hubner G, et al. Solitary fibrous tumour of the pancreas: a new member of the small group of mesenchymal pancreatic tumours. Virchows Arch 1999;435:37-42.

9 Chilosi M, Facchettti F, Dei TA, et al. bcl-2 expression in pleural and extrapleural solitary fibrous tumours. J Pathol 1997;181:362-367.

10 Suster S, Fisher C, Moran CA. Expression of bcl-2 oncoprotein in benign and malignant spindle cell tumors of soft tissue, skin, serosal surfaces, and gastrointestinal tract. Am J Surg Pathol 1998;22: 863-872.

11 Shidham VB, Chivukula M, Gupta D, et al. Immunohistochemical comparison of gastrointestinal stromal tumor and solitary fibrous tumor. Arch Pathol Lab Med 2002;126:1189-1192.

12 Huizinga JD, Thuneberg L, Kluppel M, et al. W/kit gene required for interstitial cells of Cajal and for intestinal pacemaker activity. Nature 1995;373: $347-349$

13 Isozaki K, Hirota S, Nakama A, et al. Disturbed intestinal movement, bile reflux to the stomach, and deficiency of c-kit-expressing cells in Ws/Ws mutant rats. Gastroenterology 1995;109:456-464.

14 Kitamura Y, Go S, Hatanaka K. Decrease of mast cells in $\mathrm{W} / \mathrm{Wv}$ mice and their increase by bone marrow transplantation. Blood 1978;52:447-452. 
15 Maeda H, Yamagata A, Nishikawa S, et al. Requirement of c-kit for development of intestinal pacemaker system. Development 1992;116:369-375.

16 Russell ES. Hereditary anemias of the mouse: a review for geneticists. Adv Genet 1979;20:357-459.

17 Nagata H, Worobec AS, Oh CK, et al. Identification of a point mutation in the catalytic domain of the protooncogene c-kit in peripheral blood mononuclear cells of patients who have mastocytosis with an associated hematologic disorder. Proc Natl Acad Sci USA 1995; 92:10560-10564.

18 Hirota S, Isozaki K, Moriyama Y, et al. Gain-of-function mutations of c-kit in human gastrointestinal stromal tumors. Science 1998;279:577-580.

19 Miettinen M, Virolainen M, Maarit SR. Gastrointestinal stromal tumors-value of CD34 antigen in their identification and separation from true leiomyomas and schwannomas. Am J Surg Pathol 1995;19:207-216.

20 Rudolph P, Chiaravalli AM, Pauser U, et al. Gastrointestinal mesenchymal tumors-immunophenotypic classification and survival analysis. Virchows Arch 2002;441:238-248.

21 Cunningham RE, Abbondanzo SL, Chu WS, et al. Apoptosis, bcl-2 expression, and p53 expression in gastrointestinal stromal/smooth muscle tumors. Appl Immunohistochem Mol Morphol 2001;9:19-23.
22 Noguchi T, Sato T, Takeno S, et al. Biological analysis of gastrointestinal stromal tumors. Oncol Rep 2002; 9:1277-1282.

23 Paner GP, Silberman S, Hartman G, et al. Analysis of signal transducer and activator of transcription 3 (STAT3) in gastrointestinal stromal tumors. Anticancer Res 2003;23:2253-2260.

24 Yamaura K, Kato K, Miyazawa M, et al. Stromal tumor of the pancreas with expression of c-kit protein: report of a case. J Gastroenterol Hepatol 2004;19: 467-470.

25 Becker EL. International Dictionary of Medicine and Biology, Vol. II. Wiley and Sons: New York, 1986.

26 Burt TB, Condon VR, Matlak ME. Fetal pancreatic hamartoma. Pediatr Radiol 1983;13:287-289.

27 Öberg-Welsh C, Sandler S, Andersson A, et al. Effects of vascular endothelial growth factor on pancreatic duct cell replication and the insulin production of fetal islet-like cell clusters in vitro. Mol Cell Endocrinol 1997;126:125-132.

28 Esposito I, Kleeff J, Bischoff SC, et al. The stem cell factor-c-kit system and mast cells in human pancreatic cancer. Lab Invest 2002;82:1481-1492.

29 Welsh M, Anneren C, Lindholm C, et al. Role of tyrosine kinase signaling for beta-cell replication and survival. Ups J Med Sci 2000;105:7-15. 